\title{
WALTER BENJAMIN: TEMPO DE ESCOLA - TEMPO DE AGORA. PROLEGÔMENOS PARA UMA EDUCAÇÃO PARA DIAS FERIADOS
}

\author{
Angela Medeiros Santi*
}

Eu sempre quis isso mesmo: armar hieróglifos com pedaços de tudo, restos de filmes, gestos de rua, gravações de rádio, fragmentos de TV.

(Fausto Fawcet)

\begin{abstract}
RESUMO: O propósito deste artigo é relacionar o pensamento de Walter Benjamin com o universo da educação e da infância, através da noção de tempo. A infância, para Benjamin, representa a suspensão do tempo vazio e linear, em favor de um tempo "artístico", um tempo de "dias feriados". A educação, em sua forma tradicional, trabalha com a formação da criança para o tempo linear, mas a infância, em sua potência revolucionária, é a suspensão do tempo como repetição mecânica, em favor de um tempo artístico, um "tempo de agora". Com base na constelação conceitual construída por Benjamin, pretendemos pensar uma agenda voltada para o futuro da educação, onde a escola deve, então, voltar seus investimentos para o tempo intensivo, o das surpresas, o dos cortes, o do inusitado. $\mathrm{O}$ artigo aponta para a educação pensada como experiência de outra temporalidade - aquela que se faz num encontro intensivo entre coisas e pessoas, livre e aberto para o inédito, aberto para o radical e para o agora.
\end{abstract}

Palavras-chave: Futuro da educação. Walter Benjamin. Infância. Tempo de agora.

\section{WALter Benjamin: time of SCHOOL - TIME OF THE PRESENT. Prolegomenon to AN EDUCATION FOR HOLIDAYS}

ABSTRACT: The purpose of this article is to relate the thoughts of Walter Benjamin with the universe of education and childhood through the track of time. For Benjamin, the childhood represents an interruption of the time line and the emptiness regarding an "artistic" time of "holidays". The education in its traditional form works with the education of children as a time line, but childhood in its revolutionary power is the interruption of time as a mechanical repetition in favor of an artistic time which is "a time of present".

Doutora em Filosofia e professora adjunta de Filosofia da Educação, Faculdade de Educação da Universidade Federal do Rio de Janeiro (UFRJ). E-mail: am-santi@uol.com.br 
Based on this concept built by Benjamin, we can consider a schedule faced for the future of the education where the school should use its investments for full time, the time of surprises, of interruptions, and the unexpected. This paper shows the education as an experience of another time - a time for an intensive encounter among things and people free and opens for the new, and open for the radical and for the present time.

Key words: Future of education. Walter Benjamin. Childhood. The present time.

\section{Walter Benjamin: temps de l'ecole - temps de maintenant. Prolegomenes POUR UNE EDUCATION POUR JOURS FERIES}

RÉSUMÉ: Le propos de cet article est de mettre en relation la pensée de Walter Benjamin avec l'univers de l'éducation et de l'enfance à travers la notion de temps. L'enfance, pour Benjamin, représente la suspension du temps vide et linéaire, en faveur d'un temps "artistique", un temps de "jours fériés". L'éducation, dans sa forme traditionnelle, travaille à l'éducation de l'enfant pour le temps linéaire, mais l'enfance, dans sa puissance révolutionnaire, est la suspension du temps comme répétition mécanique, en faveur d'un temps artistique, un "temps de maintenant". A partir de la constellation conceptuelle construite par Benjamin, nous voulons penser un programme tourné vers le futur de l'éducation, où l'école doit, alors, orienter ses investissements pour le temps intensif, celui des surprises, celui des coupures, celui de l'inhabituel. L'article propose une éducation conçue comme expérience d'une autre temporalité - celle qui se fait dans une rencontre intensive entre choses et personnes, libre et ouverte à l'inédit, ouverte au radical et au maintenant.

Mots-clés: Futur de l'éducation. Walter Benjamin. Enfance. Temps de maintenant.

$\mathrm{P}$

ensar a tarefa da educação e seus modos de operação na contemporaneidade é o propósito deste artigo. A educação pode ganhar muito se deixar de girar exclusivamente em torno de questões cognitivas, associadas ao encadeamento significativo, linear e lógico, para se abrir à dimensão do novo, através de uma relação intensiva e criadora com o mundo e seus elementos. O processo da educação, entendido como experiência fundadora capaz de constituir indivíduos aptos a ler e criar a si e o mundo, é o que pensamos poder construir no desenvolvimento deste texto, acompanhados da rica constelação de categorias que encontramos em Walter Benjamin.

Nossa reflexão pretende operar, então, a conexão de noções presentes no pensamento de Benjamin e outras relacionadas à educação, à escola e à infância (da educação, das pessoas). Para isso, propomos um passeio e nos dispomos a apresentar as peças que fazem parte de nossa oficina conceitual, visando pensar outras possibilidades de futuro para a educação. O eixo central desta oficina está na noção de tempo, considerando a potência transformadora que ela guarda ao ser pensada no universo da educação. 


\section{Peça de montagem n. 1: o tempo}

A infância, para Walter Benjamin, é a suspensão do tempo vazio e linear, próprio da modernidade, em favor de um tempo "artístico", um tempo de "dias feriados", como diz o autor. O tempo da infância é também o tempo da história, tal como Benjamin a entende: como encontro intensivo de uma temporalidade não causal, mas intermitente. Aqui, rompe-se com o tempo como repetição mecânica e abre-se a possibilidade de uma experiência também intensiva, "estética". Benjamin considera que o tempo dos relógios é vazio, sempre igual, o dos calendários é irregular, carregado de presenças. A sua concepção, na verdade, concentra-se na experiência de um tempo pré-capitalista ou pré-industrial, que guarda em seus calendários e suas festas os vestígios da consciência histórica do tempo. Por exemplo, a atitude de atirar contra os relógios de Paris, em julho de 1830, que aconteceu aleatoriamente em vários pontos da cidade, indicava, para Benjamin, esse potencial revolucionário de suspensão do tempo linear, intuído, de alguma forma, pelos rebeldes.

Para Benjamin, os calendários representam o contrário do tempo vazio: são expressão de um tempo histórico, heterogêneo, carregado de memória e de atualidade. Os feriados são qualitativamente distintos dos outros dias: são dias de lembrança, de rememoração, que expressam uma verdadeira consciência histórica. (Lowy, 2005, p. 124)

A questão do tempo (e da infância), para ele, é uma questão política porque o foco de sua luta "ideológica" está aí. O tempo que aprisiona, sufoca e representa a aspiração da modernidade burguesa é o tempo em progresso, linear e sequencial. É contra esse tempo morno, morto, que Benjamin irá se voltar através das noções de origem, tempo de agora, imagem dialética, e todo o seu repertório teórico e revolucionário que nosso autor constrói. Tal repertório servirá como manancial bélico para a interrupção de um tempo (e um pensamento) repressivo. Como em um relampejar, as estruturas da história, da escola e da infância surgem, assim, de modo novo, imperativo. Deste modo, e só deste, esse "surgimento" é possível porque ele se apresenta sem um antes ou um depois necessários, como potência do atual, para "por luz" à atualidade e transformá-la, abrindo-a para as exigências do agora.

Essa temporalidade pontual (tal como um relampejar) é o "tempo de agora" (Jetztzeit), a origem atual da identidade do presente. A origem difere-se da gênese, que é justamente uma origem mecânica, aquilo que veio antes e não aquilo que surge, num determinado momento, para fundar uma história, um sentido. Mas, para Benjamin, esse tempo atual, potente, só se configura deste modo porque este presente não está vazio, mas porque ele se conecta com o passado, resgatando-o, 
redefinindo-o. Tal dinâmica Benjamin nomeia, em sua obra, de "imagem dialética", sendo esta a "constelação do ocorrido com o agora: não temporal, mas dialética" (Seligmann-Silva, 1999, p. 228), que se caracteriza por sua imediaticidade:

(...) não é que o passado lança sua luz sobre o presente ou que o presente lança sua luz sobre o passado; mas a imagem é aquilo em que o ocorrido encontra o agora num lampejo, formando uma constelação. Em outras palavras: a imagem é a dialética na imobilidade. Pois, enquanto a relação do presente com o passado é puramente temporal e contínua, a relação do ocorrido com o agora é dialética - não uma progressão, e sim uma imagem, que salta. (Benjamin, 2006, p. 504)

Assim, Benjamin mostra que a história só ganha sua legitimidade se consegue apresentar-se como imagem (porque imediata/condensação) dialética (porque imagem congelada de opostos), na medida em que precisamente supera a "progressão" cega da história e suspende o tempo, tornando-se história através do espaço, historiografia - uma história impressa nas coisas e não nas conexões (temporais) já estabelecidas sobre elas. Tal como afirma Bolle (2000, p. 67), o historiador, para Benjamin, "aparece aí no papel do detetive, prestes a investigar os rastros de um crime (...)". Benjamin pensa num historiador treinado para identificar as imagens dialéticas que revelam a cada tempo sua identidade: em relação ao seu grande objeto de estudo, o século XIX, as imagens dialéticas que lhe identificam são as passagens de Paris que são, ao mesmo tempo, espaço público e privado, lugar de compra e de culto.

A imagem dialética evidencia a história como descontínua, aos saltos, irregular. A história como "irregularidade" nos dá a condição de pensar: como podemos construir uma história "irregular" para a escola, rompendo com o tempo linear onde só se pode tecer sentidos já determinados? Buscando rastros, tal como o detetive no qual Benjamin pretende transformar todo pensador? A questão aberta nos lança em direção a outra peça fundamental para a nossa reflexão: a infância. É ela que pode nos colocar na rota da construção de um novo tipo de escola e de educação, evidenciando os indícios dispersos na paisagem do atual. Passeemos por ela.

\section{Peça de montagem n. 2: a infância}

A infância, para Benjamin, indica uma relação entre o universo microscópico e o macroscópico (a infância em si, a da sua geração e a infância da modernidade) e se constitui como uma dimensão política fundamental, dada a sua capacidade de acionar o passado e a história. A infância é a chave da experiência perdida para o adulto, que o coloca de novo na possibilidade de criação de um tempo (e de uma experiência) não mecânico, não aprisionador. $\mathrm{O}$ tempo não linear é a potência do sentido dado agora, a cada agora, e a criança é aquela que descobre o "novo de novo" e, 
através dessa experiência, instrui a todos a como fazer o mesmo. Susan Buck-Morss afirma, com relação a esta questão, que

(...) a história era patrimônio das crianças e, como tal, era sempre um retorno aos inícios. Aqui se apresentam as revoluções não como culminação da história do mundo, mas como um novo começo: "o instante 'um' chega", escreve Benjamin a propósito de, e não acidentalmente a, sua viagem a Moscou, "o estágio infantil começa quando, por causa das ruas geladas, até andar tinha que ser aprendido de novo. (Buck-Morss, 2002, p. 316-317)

Como retorno "aos inícios", a criança é aquela que permite a operação de, ao estar no tempo presente, acionar o passado como atual; atualizar o sentido do passado, recuperar suas promessas perdidas e esquecidas. Essa dinâmica representa aquela da história e, através da imagem dialética, o passado encontra o presente num agora, que irrompe num relampejar, capaz de ativar utopias apagadas pelo tempo. Como a criança é, em si, o dispositivo que aciona uma experiência viva do passado no atual, ela torna-se uma peça fundamental da "caixa de ferramentas" de Benjamin.

O passado que interessa a Benjamin é aquele que se relaciona com o seu presente; neste sentido, ele estuda, no início do século XX, o século XIX, como chave de compreensão do (seu) tempo atual. Como o tempo, para ele, apresenta-se no espaço, nas imagens que cada tempo fornece de si mesmo, o tempo do século XIX encontrase forjado nas passagens, tal como já havíamos anunciado. O século XIX e as passagens são a infância do século XX. Ali, "pela primeira vez, o passado mais recente se torna distante" (idem, ibid., p. 94):

(...) chegando ao século $X X$, as passagens originais tinham fracassado financeiramente porque suas pequenas lojas especializadas em bens de luxo não podiam mais competir com as grandes galerias de departamento, que vendiam mercadorias produzidas em massa a um ritmo rápido o bastante para compensar as quedas da taxa de juros. (p. 95)

Nas passagens, misto de espaço privado e público, prenúncio das lojas de departamento e dos shoppings, a modernidade mostra a sua verdadeira face: a do novo que já é velho, a do novo que é repetição do mesmo, e que se apresenta exemplarmente na moda. Benjamin quer estudar o passado recente porque ele contém o paradoxo do "recém acontecido" e do "irremediavelmente perdido". Como característica da modernidade, o que acabou de acontecer como promessa do novo é corroído automaticamente pelo outro novo, e a novidade passa a ser a face mortuária do atual. Desse modo, Benjamin consegue revelar a modernidade como mito e o progresso como eterno retorno do mesmo (do novo como repetição do mesmo, como morte), denunciando sua potência regressiva e sua força repressiva. 
Diante desse cenário, da modernidade como mito, a infância surge como uma poderosa força: ela lembra à modernidade suas promessas e a coloca em xeque ao contrastá-la com o que está dado - quebrando com o encantamento do mito. Conforme nos diz Buck-Morss (op. cit.), a criança relembra o momento histórico em que a tecnologia foi concebida, reativa a memória da promessa da industrialização como a de abundância material - a possibilidade de, pela primeira vez, a humanidade poder produzir em abundância tudo de que precisa, saindo de um "estado de natureza". Assim, a criança possui o poder de acionar utopias, na medida em que ela própria encarna as contradições da realidade, exigindo que suas promessas se cumpram.

Sendo assim, se por um lado a educação é o locus da criança e de todo o seu poder subversivo, por outro ela é a ferida aberta da contradição do que a educação e a escola são: projeto de utopia e lugar de conservação do status quo. Desse modo, podemos pensar: qual é a promessa não cumprida da educação? O que ela deixa de cumprir, a quais propósitos ela trai? Como podemos atualizar tais promessas, através da subversão do tempo linear, permitindo que a irrupção de experiências intensivas, que interrompem o programa já determinado, seja acolhida e considerada na construção de uma nova lógica educacional?

A atividade lúdica na criança é capaz de trazer à tona aquilo que são as fendas e as feridas, que são as promessas não cumpridas pela modernidade industrial. As crianças

(...) sentem-se irresistivelmente atraídas pelos detritos que se originam da construção, do trabalho no jardim ou na marcenaria, da atividade do alfaiate ou marceneiro. Nesses produtos residuais, elas reconhecem o rosto que o mundo volta exatamente para elas, e somente para elas. Neles, estão menos empenhadas em reproduzir as obras dos adultos do que em estabelecer, entre os mais diferentes materiais, através daquilo que criam em suas brincadeiras, uma relação nova e incoerente. (Benjamin, 2002, p. 104)

A criança subverte a experiência pela maneira como procede com os objetos e é em si mesma a própria subversão, porque desrespeita a ordem e o sentido estabelecido. Como se soubesse do caráter provocativo, insubordinado, de tal atitude, a criança deseja mais tudo aquilo que não foi destinado a ela: ela quer os farrapos, os detritos, o lixo. É como se esses materiais estivessem mais disponíveis ao jogo e ao seu caráter construtivo e criativo. No jogo, desse modo, conforme afirma BuckMorss (2002, p. 317), "a cognição das crianças tem o poder revolucionário porque é tátil, ligada à ação, e porque em vez de aceitar o sentido dado das coisas, as crianças conheciam os objetos ao fazê-los e usá-los criativamente, deles liberando novas possibilidades de significado".

Nesse mesmo sentido, Benjamin faz referência a um antigo jogo que se constitui de frases que se formam a partir de palavras soltas: "que se indiquem quatro 
ou cinco palavras determinadas para que sejam reunidas em uma curta frase (...)" (Benjamin, 2009, p. 70). Tal jogo é a manifestação exata do método de Benjamin. A realidade se compõe de elementos que não formam totalidades definidas e definitivas: "de repente, as palavras vestem seus disfarces e num piscar de olhos estão envolvidas em batalhas, cenas de amor e pancadarias (idem, ibid.). As palavras são dadas e a totalidade é construída por quem joga, quando joga, sem caráter necessário. Assim jogando, a criança constitui, à sua maneira, um mundo e nele uma herança, tão ingênua quanto potente, que aguarda o tempo de despertar.

A alquimia que resulta da brincadeira revela, na incoerência de suas combinações, a incoerência da própria realidade. Assim, Benjamin, tal como a criança, em oposição ao discurso e ação megalomaníaca, monumentalista, onipotente e progressista do século XIX, busca "nos objetos pequenos e descartados, nos edifícios antiquados e estilos fora-de-moda, que, precisamente como 'lixo' da história, eram evidência de sua destruição material sem precedentes" (Buck-Morss, 2002, p. 125), a "linha de fuga" que permitirá à sua época a sua libertação. De dentro, a criança e o pensador operam a subversão do progresso e do otimismo repressor, ao elegerem materiais pouco nobres e ao expô-los com destaque, como se nobres fossem.

O trabalho da criança, seu modo de operar, traz à tona as incoerências do real, constitui-se como dimensão reflexiva e apresenta-se como antídoto (na medida em que apresenta a ferida aberta e a dinâmica de suas contradições). Ao duplicar o real, com outros elementos e, principalmente, com outra lógica de composição destes elementos, a infância cria para a modernidade a oportunidade de se ver refletida. $\mathrm{O}$ caráter propositivo que a atividade, o modo de operação, da criança traz é o de poder ser esse o espaço de duplicação, o mostrar sem julgamento, que revela a quem o vê o mundo como incoerente e inacabado. Ao ver coincidir o destino da criança e do coletivo, da infância e da história, Benjamin aponta para a potência libertadora da própria história que a criança realiza ao brincar. Tal potência encontra-se na imitação.

Segundo Benjamin, “o jogo das crianças está impregnado de formas miméticas de comportamento (...)" (Buck-Morss, op. cit., p. 125). Se essas formas miméticas mudam historicamente, como entende o autor, elas estariam presentes nas novas tecnologias - em sua época, estariam presentes no cinema, principalmente.

O cinema, como arte reprodutiva associada ao capitalismo industrial, colocaria em colapso a percepção ordinária "pela aceleração do tempo e fragmentação do espaço":

Se a industrialização causa uma crise na percepção pela aceleração do tempo e pela fragmentação do espaço, o filme mostra uma cura potencial ao desacelerar o tempo e, através da montagem, constrói realidades sintéticas como novas ordens espaço-temporais, segundo as quais as "imagens fragmentadas" se juntam "de acordo com uma 
nova lei". (...) O filme proporciona uma capacidade para estudar a existência moderna reflectivamente, desde "a posição de um perito". (Idem, ibid., p. 320)

A infância, através da mesma dinâmica que o cinema possui, contém a senha de acesso que permite a reversão dos efeitos repressivos e paralisantes das novas tecnologias. Assim como no filme, a capacidade mimética da criança não possui apenas uma dimensão de reprodução, mas também, e principalmente, de criação de algo novo pela repetição. A imitação, na brincadeira da criança ou na experiência do impacto na percepção do espectador no cinema, permite que, em função desta duplicação, o homem desperte e se reaproprie da experiência pela ação. O ritmo violento e inumano da linha de montagem, "que bombardeia os sentidos com imagens desconexas e estímulos cujos efeitos eram choques" (idem, ibid., p. 125), é redimensionado ao ser duplicado pelo homem, apresentando-se como arte e espelho, abrindo uma dimensão reflexiva e libertadora.

Assim, Benjamin "transforma o veneno em remédio", na medida em que o próprio fenômeno que põe em colapso a apreensão "ordinária" do real traz seu antídoto, ou melhor, sua dimensão revolucionária. Tal processo, que impacta e amortiza, pode ser usado também neste sentido: para reconstruir a experiência, desarticulada pela industrialização.

Tais reflexões nos dão pistas de um método pedagógico: a reconstrução da experiência como tarefa da educação, que usa os recursos típicos da atualidade como antídoto para seus próprios "males". O recurso parte da duplicação, de uma sistemática do espelho, que expõe aquilo que os homens vivem como destino, transformando essa experiência em reflexão, ou, mais exatamente, em experiência (num sentido forte, "benjaminiano"1), quebrando seu "feitiço", libertando os homens da história (desta história que Benjamin denuncia, da história que é mito). A educação mostraria as suas próprias contradições e poderia, então, abrir-se para o novo.

A infância da educação, através desses elementos, pode ser potencializada se pensada como experiência de recuperação dos detritos do mundo, de duplicação dos elementos que a caracterizam, bem como de subversão da ordem das coisas e do tempo - a subversão dada pela implosão do tempo linear. Assim, ao invés da postura ressentida e reativa da escola e dos professores com os elementos que a caracterizam, o exercício proposto, a partir de Benjamin, é o de imersão na cultura, o de decomposição de seus elementos e de, a partir disso, o da construção de uma dimensão positiva, ativa, por parte de alunos e instituições de ensino. Sendo assim, atualmente, os elementos dos meios de comunicação de massa, a publicidade, os reality shows podem ser o lugar por excelência de nosso mergulho pedagógico e reflexivo. Nesse sentido, a educação coloca-se hoje no centro da problemática da própria modernidade, na medida em que se encontra imersa nos seus pressupostos, 
sendo dela derivada e, ao mesmo tempo, possuindo capacidade de "transcendência" (capacidade reflexiva), podendo ser sua dimensão crítica. Dessa forma, a educação coloca-se no centro de nossas questões e será agora mais especificamente analisada.

\section{Peça de montagem n. 3: a educação}

O tempo da escola, como o tempo da infância, significa inventar (ou recuperar, reinventando) um novo modo de existir da escola que permita as operações que a infância processa e que são a expressão e a garantia da própria vitalidade de toda a experiência. A infância, tal como a entende Benjamin, representa a subversão de todos os sentidos fixados nas coisas. Esta fixação funciona como um toque de Midas, que congela definitivamente as coisas em uma configuração unívoca. Ao aprisionar as coisas, impedindo que elas componham com o mundo e transformem-se, morrem as coisas e morrem as infâncias - das pessoas, das escolas. Assim, para libertar as coisas, a educação precisa correr riscos. Como diz Benjamin (1993, p. 73),

(...) saber orientar-se numa cidade não significa muito. No entanto, perder-se numa cidade, como alguém se perde numa floresta, requer instrução. Neste caso, o nome das ruas deve soar para aquele que se perde como o estalar do graveto seco ao ser pisado, e as vielas do centro da cidade devem refletir as horas do dia tão nitidamente quanto um desfiladeiro.

A educação pode constituir-se também através dos desvios, dos silêncios, do não saber, que é onde um novo saber e um novo modo de ser da escola podem constituir-se. Perder-se! Tal processo significa tornar-se plenamente disponível para o aqui e agora, ativando a sensibilidade para perceber todos os sinais do real que indiquem pistas para podermos ler o nosso tempo e inscrever adequadamente os hieróglifos, indicando o que somos e o que pode ser a educação. A escola pode instruir os alunos a orientar-se (ou melhor, perder-se) diante dos códigos de seu mundo e seu tempo, capacitando-os a reconhecer pequenos indícios, como o "estalar do graveto seco", e decodificá-los. Benjamin dirá que, "através dos nomes das ruas, a cidade torna-se um cosmos linguístico. Palavras são nomes de firmas e seus textos são fundamentalmente prospectos de empreendimentos que ainda não foram estabelecidos" (Seligmann-Silva, 1999 p. 121). Para ele, "as coisas expressam verbetes de um dicionário secreto" (idem, ibid.) e esperam por uma interpretação fundadora, que pode acontecer para que elas próprias possam de fato existir. À educação cabe habilitar-se para dar aos estudantes a potência decifradora do atual.

De certa forma, este é o duplo papel da escola e da educação: instruir os alunos a identificar os códigos de seu tempo e, também, instruí-los a construir - montar - com os elementos que os constituem, “hieróglifos com pedaços de tudo, restos de filmes, 
gestos de rua, gravações de rádio, fragmentos de TV", como diz a epígrafe na abertura deste texto, de modo que os estudantes possam decodificar e produzir história.

Tais tarefas, dadas à escola por uma agenda voltada para o futuro da educação, exigem a experiência de outra temporalidade: tal como Benjamin concebe, com relação à linguagem e à história, há um tempo "intensivo" e outro "comunicativo", derivado. A escola trabalha com o segundo, o tempo da legibilidade, discursivo, encadeado, linear e lógico. Benjamin refere-se a tais categorias com relação, principalmente, à questão da linguagem, mas aqui as tomaremos emprestadas para pensar outra escola e outro "modelo" de educação. Benjamin dirá que a linguagem possui uma dimensão intensiva, contrária à significação, autorrefencial, refratária, então, a sentidos pré-determinados. Tal dimensão colocaria a linguagem não só como portadora de significados, mas como corpo material, como imagem (como acontece com a escrita chinesa ou japonesa). A outra dimensão, a comunicativa, coloca o corpo da linguagem como meio que contém um conteúdo, um sentido a ser interpretado, onde se tem a linguagem no seu sentido habitual.

A primeira dimensão, nós a temos como imagem, cuja recepção está ligada à recepção visual, apreendida pelo impacto. Tal dimensão coloca em exercício uma experiência ligada àquela da imagem - condensação de informações em uma "totalidade" autorreferencial, sem uma legibilidade encadeada, sequencial e linear. Tal exercício significa um contato primeiro, inédito, associado mais ao impacto "físico", perceptivo, do que ao aprisionamento significativo. Aqui é possível ver nascer algo novo, fruto do "livre jogo" entre pessoas e coisas, entre mundos e infâncias, entre tempos passados e atuais. Da mesma forma, é assim que é possível construir uma educação de uma maneira nova, voltando-a para a dinâmica da recepção visual e não a da discursiva - educação voltada para o impacto intensivo de um fragmento que se apresenta (Darstelung), se expõe como totalidade, no agora, em um instante, sem um antes e um depois, livre.

A escola pode resgatar a experiência equivalente à linguagem intensiva e à recepção visual, construindo, automaticamente, um tempo igualmente intensivo. A educação possui o desafio de estruturar um processo de aprendizagem que possa incorporar, ser receptivo ao "tempo de agora", criando condições de uma vivência "que guarda em si seus calendários e suas festas", acionando seu poder, indicado pelo poder da criança, de "retorno aos inícios". Tal proposta e tal desafio para a educação aparecem como o antídoto para o poder demolidor do tempo que tudo corrói - o tempo que ganhamos como herança da modernidade e que se constitui no centro das críticas feitas por Benjamin: o da consumação do novo, o da "maldição" mítica da corrupção do novo pelo "mais novo", do novo que já nasce velho.

O que pode fazer com que saiamos desse ciclo de nascimento que é morte, que condena toda a atividade, inclusive a escolar, a ser a repetição do mesmo, que 
impede que algo novo verdadeiramente se crie, é esse ponto de fuga que significa uma imersão no real, uma espécie de descida ao inferno do que somos e vivemos (ao invés de sua negação): uma imersão na cultura, no universo das mídias e das imagens, para devorarmos seu modus operandi e nos apropriarmos de seus poderes. Tal como colocamos anteriormente, o modo de nos apropriamos de nosso tempo se dá através da apropriação dos objetos de nosso tempo, de seus corpos e suas linguagens. Assim, o modus operandi da escola pode se efetivar através da incorporação e mimeses das novas tecnologias e das (novas) mídias. É incorporando-as que conseguimos desmontá-las e superá-las.

O desafio está em incluir este aspecto na dinâmica muitas vezes pesada da educação institucionalizada, enrijecida por demandas burocráticas. Mas essa inclusão não é exclusiva, não pretende substituir a dimensão discursiva, lógica, do ensino, onde, justamente, o conhecimento se faz. Apenas, tal dinâmica lembra (propõe, para ser exato) que a educação não se restringe à dimensão do conhecimento, ela possui também uma dimensão viva de rompimento e criação, irrupção e impacto, de experiência. Tal experiência é inaugural, criativa e criadora, podendo fundar, a partir de si, um novo conjunto de conhecimentos, discursos, encadeamentos. Esta dimensão associa-se a um movimento irregular, descontínuo e desestruturador, com o qual a escola não tem conseguido lidar, recalcando-o secularmente.

A educação, em sua forma tradicional, trabalha com a formação da criança para o tempo e o espaço lineares. É através da institucionalização do tempo que se produz a domesticação necessária ao mundo adulto, voltado para o trabalho. A criança não se encaixa no mundo dos adultos, ela se apresenta como uma dimensão incômoda porque possui a capacidade de ativar utopias. Ela vai ao mundo para se apropriar dos objetos, desrespeitando todo o sentido pré-fixado, todo tempo pré-estabelecido. A infância, em sua potência revolucionária, é a suspensão do tempo linear, morto, em favor de um tempo artístico que é capaz de romper com a experiência do tempo como repetição mecânica.

A escola pode, então, voltar seus investimentos para o tempo intensivo, o das surpresas, o dos cortes, do inusitado, que se apresenta num agora não planejado, um tempo de dias feriados! Esta educação, este tempo, constitui-se de pequenos (ou grandes) desvios de rota conforme irrompam situações inusitadas, reações não esperadas, alquimias impensadas. Tal ensino pode contar com professores "treinados" para perceber pequenas (e grandes) faíscas de reações inéditas; professores capazes de parar neste ponto, considerá-lo, incorporá-lo e alterar o planejamento em função delas, de modo vivo, orgânico. Poderíamos conceber, a partir da disponibilidade desta "escola do futuro", algo como um efeito "tsunami": uma educação onde pequenos deslocamentos geram grandes transformações. 


\section{Nota}

1. A noção de experiência perpassa toda a obra de Benjamin e associa-se ao declínio de uma tradição compartilhada por uma coletividade. O autor opõe a ideia de experiência (Erfahrung) à de vivência (Erlebnis), considerando a primeira como ligada a uma memória comunitária, própria a várias gerações, e a segunda, à sua versão decaída, associada à vivência do indivíduo solitário.

\section{Referências}

BENJAMIN, W. Obras Escolhidas II. 3. ed. São Paulo: Brasiliense, 1993.

BENJAMIN, W. Reflexões sobre a criança, o brinquedo e a educação. São Paulo: Duas Cidades; Editora 34, 2002.

BENJAMIN, W. Passagens. Belo Horizonte: UFMG; São Paulo: Imprensa Oficial do Estado de São Paulo, 2006.

BENJAMIN, W. Reflexões sobre a criança, o brinquedo e a educação. São Paulo: Duas Cidades; Ed. 34, 2009.

BOLLE, W. Fisiognomia da metrópole moderna. 2. ed. São Paulo: Edusp, 2000.

BUCK-MORSS, S. Dialética do olhar: Walter Benjamin e o Projeto das Passagens. Belo Horizonte: UFMG; Chapecó: Argos, 2002.

LÖWY, M. Walter Benjamin: aviso de incêndio; uma leitura das teses "Sobre o conceito de história". São Paulo: Boitempo, 2005.

SELIGMANN-SILVA, M. Ler o Livro do Mundo: Walter Benjamin: romantismo e crítica literária. São Paulo: Iluminuras; Fapesp, 1999.

Recebido em 18 de outubro de 2010.

Aprovado em 27 de julho de 2011. 